\title{
Making Your Mind Up? The Reliability of Children's Survey Responses
}

\author{
Matthew Horton \\ University of Central Lancashire \\ Preston, UK \\ mplhorton@uclan.ac.uk
}

\author{
Janet C Read \\ University of Central Lancashire \\ Preston, UK \\ jcread@uclan.ac.uk
}

\author{
Gavin Sim \\ University of Central Lancashire \\ Preston, UK \\ grsim@uclan.ac.uk
}

\begin{abstract}
Survey tools are widely used within Child Computer Interaction however the validity and reliability of children's responses are often brought into question. This paper reports on a study on the effects of asking the same questions to the same children over a period of a week to ascertain the validity of children's responses when completing a single questionnaire. The results showed that over $50 \%$ of the children, for each question, had less than half the items they stated as having at home in their results for both questionnaires questioning the validity of either questionnaire alone. Further research will look at the differences in time gaps and use of identical questionnaire styles.
\end{abstract}

\section{Child Computer Interaction. Survey Methods. Technology.}

\section{INTRODUCTION}

Survey tools are widely used within the child computer interaction domain to elicit information from children as part of the design or evaluation process (Horton \& Read, 2008). There are many methods which are reliant on an appropriately designed and valid survey tool such as the Fun Toolkit (Read et al, 2002), This or That (Zaman, 2009). In using surveys concerns arise over the validity of the data due to satisficing, the use of appropriate language (Borgers \& Hox, 2001) and evaluator bias (Borgers et al, 2004). Studies that have been conducted with children have validated the tools for internal consistency based on a number of constructs but there is limited research into the reliability of the tools over time. This paper aims to investigate whether there is consistency in response to survey instruments within the context of children's understanding of technology within their home. This work will enable researchers to understand the limitations of children's responses and help improve the validity and reliability of existing methods.

\section{METHOD}

This research was carried out in a local primary school using 19 children aged 6 and 7 from a year 3 (KS2) class. All children within the class were given the option to take part in the study and the children were told they could stop participating in the research at any time.
The children were given a pictoral questionnaire and asked to stick pictures of the technologies they had at home on the picture of the house. A week later the children were given a written version of the same questionnaire, using the same questions and same technologies and asked to tick the technologies that they had in their homes.

\section{RESULTS}

The results from each question have then been split showing technologies that were chosen only in the pictoral questionnaire, technologies that were chosen in both questionnaires and then technologies that were only chosen in the written questionnaires. The final column shows the percentage of technologies that were chosen by each child that appeared in the results from both questionnaires.

Table 1: Children's results from the two questionnaires

\begin{tabular}{|c|c|c|c|c|}
\hline Child & $\begin{array}{c}\text { Only } \\
\text { Pictoral }\end{array}$ & $\begin{array}{c}\text { Pictoral } \\
\text { \& Written }\end{array}$ & $\begin{array}{c}\text { Only } \\
\text { Written }\end{array}$ & $\begin{array}{c}\% \text { on } \\
\text { both }\end{array}$ \\
\hline 1 & 4 & 0 & 4 & $0 \%$ \\
\hline 2 & 2 & 1 & 5 & $13 \%$ \\
\hline 3 & 3 & 1 & 6 & $10 \%$ \\
\hline 4 & 2 & 3 & 8 & $23 \%$ \\
\hline 5 & 0 & 2 & 6 & $25 \%$ \\
\hline 6 & 2 & 8 & 0 & $80 \%$ \\
\hline 7 & 2 & 7 & 2 & $64 \%$ \\
\hline 8 & 2 & 3 & 3 & $38 \%$ \\
\hline 9 & 2 & 4 & 5 & $37 \%$ \\
\hline
\end{tabular}




\begin{tabular}{|c|c|c|c|c|}
\hline 10 & 8 & 0 & 2 & $0 \%$ \\
\hline 11 & 2 & 7 & 2 & $64 \%$ \\
\hline 12 & 1 & 9 & 1 & $82 \%$ \\
\hline 13 & 1 & 7 & 4 & $58 \%$ \\
\hline 14 & 3 & 8 & 3 & $57 \%$ \\
\hline 15 & 2 & 1 & 6 & $11 \%$ \\
\hline 16 & 4 & 7 & 1 & $58 \%$ \\
\hline 17 & 4 & 1 & 4 & $11 \%$ \\
\hline 18 & 2 & 10 & 2 & $71 \%$ \\
\hline 19 & 6 & 7 & 0 & $54 \%$ \\
\hline
\end{tabular}

The results show that $53 \%$ of the children had less than half the technologies they stated to have on both questionnaires. The majority of children with less than half the technologies had significantly lower results than this. None of the children produced the same results for a question across the two questionnaires.

\section{DISCUSSION}

This study has provided some interesting findings that do bring into question the validity of children's responses. If over $50 \%$ of the children have less than a half of the same answers on two questionnaires asking the same questions then either of these questionnaires would have produced results that look perfectly valid but are completely different and all this just one week apart. An example of this could be that one week the majority of the children could report as having computers at home where as the next week the same children state they do not. Using these findings to evidence children's computer usage could have a profound effect on an entire research study.

One area that does require further study is that of picture matching. This occurs, for example, when a child is given a pictoral questionnaire and asked if they have a computer at home. The child may have a computer but it is not the one that is pictured so because of this it is not chosen.

Not a single child on either of the questions had exactly the same result on both questionnaires. Looking at this as a comparison of the same question asked twice to the same person, none of the 19 questions resulted in exactly the same answer. If this is the case then once again how can the results from either questionnaire be valid.

Further work needs to be carried out to see if the length of time between the two questionnaires contributes to the varying results.
It is unlikely, but not impossible, that within the week between the questionnaires the households acquired all the technologies only chosen in the second questionnaire and removed the technologies only present on the second questionnaire.

\section{CONCLUSION}

This study has highlighted some serious issues with the validity of questionnaire answers given by children from the varying results that have been highlighted. Further investigation needs to be carried out to see if any methods can be found to help reduce this problem.

It is noted that this study was carried out using two different questionnaire techniques and that it is it possible this may have had an impact on the results therefore a similar study is planned following the same method but using exactly the same questionnaire each time.

\section{ACKNOWLEDGMENTS}

Our thanks to the children and teachers of English Martyrs Primary School for their participation in this research.

\section{REFERENCES}

Borgers, N. and Hox, J. (2001) "Item Non response in Questionnaire Research with Children." Journal of Official Statistics, 17(2): 321 - 335.

Borgers, N., J. Hox and Sikkel, D.(2004) "Response Effects in Surveys on Children and Adolescents: The Effect of Number of Response Options, Negative Wording, and Neutral Mid-Point." Quality and Quantity, 38(1): 17 - 33.

Horton, M. \& Read, J.C. (2008), Interactive Whiteboards in the Living Room? - Asking Children about their Technologies. The 22nd BCS British$\mathrm{HCl}$ 2008, Liverpool, UK

Read, J. C., S. J. MacFarlane and Casey, C. (2002) Endurability, Engagement and Expectations: Measuring Children's Fun. Interaction Design and Children, Eindhoven, Shaker Publishing

Zaman, B. (2009). Introducing a Pairwise Comparison Scale for UX Evaluations with Preschoolers. Human-Computer Interaction INTERACT 2009. Springer Berlin 